\title{
Molecular Mapping of Ty-4, a New Tomato Yellow Leaf Curl Virus Resistance Locus on Chromosome 3 of Tomato
}

\author{
Yuanfu Ji, Jay W. Scott ${ }^{1}$, and David J. Schuster \\ Gulf Coast Research and Education Center, University of Florida, 14625 CR 672, Wimauma, \\ FL 33598 \\ Douglas P. Maxwell \\ Department of Plant Pathology, University of Wisconsin, 1630 Linden Drive, Madison, WI 53706
}

\begin{abstract}
AdDITIONAL INDEX words. Lycopersicon esculentum, Solanum chilense, begomovirus, geminivirus, marker-assisted selection, QTL

Abstract. Resistance to begomoviruses, including bipartite tomato mottle virus (ToMoV) and monopartite tomato yellow leaf curl virus (TYLCV), has been introgressed to cultivated tomato (Solanum lycopersicum) from Solanum chilense accessions LA1932 and LA2779. A major gene, Ty-3, responsible for resistance to ToMoV and TYLCV was previously mapped on the long arm of chromosome 6. In the present study, we identified a 14-cM S. chilense introgression on the long arm of chromosome 3 in some resistant breeding lines derived from LA1932. A new begomovirus resistance locus, $T y$-4, was mapped to the 2.3-cM marker interval between C2_At4g17300 and C2_At5g60160 in the introgression. Analysis of a population segregating for $T y-3$ and $T y-4$ demonstrated that $T y-3$ accounted for $59.6 \%$ of the variance, while $T y-4$ only accounted for $15.7 \%$, suggesting that $T y-4$ confers a lesser effect on TYLCV resistance. Recombinant inbred lines (RILs) with $T y-3$ and $T y-4$ had the highest level of TYLCV resistance. The PCRbased markers tightly linked to the $T y-4$ locus as well as the $T y-3$ locus have been recently used in our breeding program for efficient selection of high-levels of begomovirus resistance and now allow for efficient breeding by marker-assisted selection.
\end{abstract}

Tomato-infecting begomoviruses, including monopartite tomato yellow leaf curl virus (TYLCV) and numerous bipartite viruses including tomato mottle virus (ToMoV), are transmitted by the sweetpotato whitefly (Bemisia tabaci), the B biotype of which is also known as the silverleaf whitefly ( $B$. argentifollii). These viruses have caused serious losses to tomato production in many tropical and subtropical regions in the world (Polston and Anderson, 1997). Although the use of insecticides for whitefly control can limit disease, epidemics can still occur, and whitefly resistance to the chemicals has been reported (Omer et al., 1993). Therefore, breeding resistant cultivars would be an effective method for control of this disease. Thus far, TYLCV resistance has not been found in Solanum lycopersicum germplasm, but has been discovered in several tomato wild species, including S. pimpinellifolium, S. peruvianum, S. chilense, $S$. habrochaites, and S. cheesmaniae (Ji et al., 2007b; Pico et al., 1996; Scott, 2007). Early breeding efforts involved the introgression of resistance genes from the wild accessions into cultivated tomato using traditional breeding approaches (Scott et al., 1996), a process that usually takes many years to breed a resistant cultivar with acceptable horticultural characteristics. Marker-assisted selection (MAS) provides a tool to improve the

Received for publication 2 Feb. 2009. Accepted for publication 12 Mar. 2009. This research was partially funded by grants from the Florida Tomato Committee and U.S. Department of Agriculture NRI grant no. 2007-3530018248 to J.W.S.

We thank Dolly Cummings, Jean Christhophe, Cathy Provenzano, and Rosa Ayala for technical assistance; Anne Kirkwood, Aaron Shurtleff, and Steve Kalb for help with virus inoculation; and Samuel Hutton and Jeremy Edwards for critical review of the manuscript.

${ }^{1}$ Corresponding author. E-mail: jwsc@uff.edu. efficiency of cultivar development. There has been significant progress in the development of markers for important tomato resistance genes (Foolad and Sharma, 2005), including numerous TYLCV resistance genes (Ji et al., 2007b). The first such gene, $T y-1$, which originated from $S$. chilense accession LA1969, was mapped near a molecular marker (TG97) on chromosome 6 of tomato (Zamir et al., 1994). PCR-based markers closely linked to the $T y-1$ gene have been developed and can be used for MAS (de Castro et al., 2007; Ji et al., 2007a). A second TYLCV resistance gene, Ty-2 (Hanson et al., 2006), which originated from S. habrochaites (Kalloo and Banerjee, 1990), was mapped to the long arm of chromosome 11 , delimited by restriction fragment length polymorphism markers TG393 and TG36 (Hanson et al., 2000). This gene was further delimited to a 4.5-cM marker interval (Ji et al., 2009). We recently identified a third begomovirus resistance gene, $T y-3$, in S. chilense accessions LA1932- and LA2779-derived resistant lines, the former carrying a $6-\mathrm{cM}$ introgression and the latter $\approx 27-\mathrm{cM}$ on the long arm of chromosome $6.7 y-3$ was mapped to the same marker interval in the two introgressions, $\approx 15 \mathrm{cM}$ away from $T y-1$ (Ji et al., 2007a). $T y$-3 differs from the first two genes mainly in two aspects. First, unlike $T y-1$ and $T y$ 2 , which are effective against only monopartite TYLCV, $T y$ - 3 is effective against TYLCV and the bipartite begomovirus ToMoV (Agrama and Scott, 2006; Ji et al., 2007a). In addition, $T y-1$ and $T y-2$ genes express complete or nearly complete dominance (Hanson et al., 2000; Ji et al., 2009; Zamir et al., 1994), while $T y-3$ is more additive (Ji et al., 2007a). $T y$-3 is a major locus explaining a high degree of the observed phenotypic variance from the two accessions, but additional resistance loci are required to obtain the highest levels of resistance 
(Ji et al., 2007a). In a previous study of TYLCV and ToMoV resistance in the backcross progenies derived from various $S$. chilense accessions, Scott et al. (1996) found multigenic control of resistance derived from $S$. chilense accessions. Inheritance studies and QTL analysis also demonstrated involvement of at least two genetic loci on chromosome 6 for TYLCV or ToMoV resistance (Agrama and Scott, 2006; Griffiths, 1998; Griffiths and Scott, 2001). Besides Ty-3, we have also searched for additional begomovirus resistance loci in the tomato genome by screening advanced resistant breeding lines derived from various $S$. chilense accessions with molecular markers on all 12 tomato chromosomes. Herein, we report the presence of a new TYLCV resistance locus, $T y-4$, in a $S$. chilense introgression on the long arm of chromosome 3 , and the construction of a molecular linkage map of the $T y-4$ locus using a population segregating for $T y-3$ and $T y-4$ loci.

\section{Materials and Methods}

Plant materials. Four advanced breeding lines derived from each S. chilense accessions LA2779, LA1932, and the intercrosses of lines derived from these two sources (LA2779/ LA1932) that displayed a high level of resistance to TYLCV and ToMoV were screened with over 400 PCR-based markers on the 12 tomato chromosomes to identify $S$. chilense introgressions in tomato genome. These lines were produced from interspecific crosses between tomato and the wild accessions, followed by four to six generations of backcrossing to tomato and six to 10 cycles of self-pollination. Selection for TYLCV and/or ToMoV resistance for over 15 years was done phenotypically by inoculation with one or the other of these pathogens, without any assistance from molecular markers before 2005. In addition to the advanced breeding lines, we also used several early breeding lines (less than five backcrosses) in the screening process, including 960719, 960729, and 960744, which were used as resistant parents in previous studies (Agrama and Scott, 2006; Griffiths, 1998; Griffiths and Scott, 2001). All three were the same for the first three backcrosses $\left(\mathrm{BC}_{3}\right)$; the latter had a different parent in the fourth $\mathrm{BC}\left(\mathrm{BC}_{4}\right)$, while the former two had the same $\mathrm{BC}_{4}$ parent but diverged in the $\mathrm{BC}_{4} \mathrm{~F}_{2}$ generation. S. lycopersicum cv. Horizon (Scott et al., 1985) was used as the susceptible control (mean disease severity $\approx 3.5$; see "Inoculation and Disease Evaluation" below), and S. chilense accessions LA2779 and LA1932 [mean disease severity $\approx 0$ (Scott et al., 1996)] were included as the resistant controls for all PCR experiments. An $\mathrm{F}_{7}$ line, 040980, derived from a cross between susceptible $S$. lycopersicum line 7655B and a begomovirus resistant line 000529, has accessions LA2779 and LA1932 in its pedigree. A population of 201 progeny from selection 040980-3 segregating for TYLCV resistance was employed to map a new TYLCV resistance locus $T y-4$.

Plant materials used in a replicated trial to analyze the effects on TYLCV resistance by combining $T y-3$ and $T y-4$ loci included RILs derived from LA2779/LA1932 containing Ty-3 alone or both $T y-3$ and $T y-4$, susceptible control 'Horizon', and resistant controls including one LA2779-derived breeding line 8602 and two commercial $F_{1}$ hybrid cultivars Tygress (Seminis, St. Louis, MO) and SecuriTY 28 (Harris Moran, Modesto, CA). Both of these hybrids are heterozygous for the $T y-1$ gene. The wild $S$. chilense accessions were obtained from Tomato Genetics Resource Center at University of California, Davis.
INOCULATION AND DISEASE EVALUATION. The inoculation procedure was the same as described by Griffiths and Scott (2001). In this procedure, seedlings are inoculated with whiteflies from a colony maintained on tomato plants that are infected with TYLCV and thus the whiteflies are viruliferous for this virus. All individual plants were rated for TYLCV disease severity three times according to the method described by Ji et al. (2007a). The third rating was used for statistical analysis to record the most accurate resistance levels of plants and to minimize the possibility of escapes (Griffiths, 1998). The rating scale was from 0 to 4 , as documented by Scott et al. (1996), where $0=$ no symptoms, 1 = slight symptoms visible only on close inspection, $2=$ intermediate symptoms visible on part of the plant, $3=$ severe symptoms over the entire plant, and $4=$ severe symptoms and stunting. Intermediate scores $(0.5,1.5$, etc.) were incorporated to allow for more precise disease severity ratings.

Field EXPERIMENTAL DESign AND STATISTICAL ANALYSis. Following inoculation, seedlings were transplanted to field plots at Gulf Coast Research and Education Center, University of Florida, Wimauma. The 201 progeny from selection 040980-3 were transplanted in one continuous block. The seven homozygous RILs and susceptible and resistant control were transplanted to the field in a randomized complete block design with three blocks and 12 plant plots. The soil in the field was Myakka, Haplaquents, and St. Johns sandy soil. The beds were raised $25 \mathrm{~cm}$ high, $71 \mathrm{~cm}$ wide at the top, and $81 \mathrm{~cm}$ wide at the base. Plants were spaced $46 \mathrm{~cm}$ apart within plots that were $92 \mathrm{~cm}$ apart in rows with $152 \mathrm{~cm}$ between rows. The beds had been fumigated with $67 \%$ methyl bromide: $33 \%$ chloropicrin at $197 \mathrm{~kg} \cdot \mathrm{ha}^{-1}$ and the beds were covered with white plastic mulch. The plants were fertilized with a total of 169 $\mathrm{kg} \cdot \mathrm{ha}^{-1}$ of nitrogen, $37 \mathrm{~kg} \cdot \mathrm{ha}^{-1}$ of phosphorus, and $210 \mathrm{~kg} \cdot \mathrm{ha}^{-1}$ of potassium throughout the season through drip irrigation. The plants were staked and tied, and sprayed with pesticides as needed throughout the season according to Olson et al. (2008).

PCR, LinkAge ANALYSIS, AND QTL MAPPING. All markers used in this study were PCR-based, including sequencecharacterized amplified region (SCAR) and cleaved amplified polymorphic sequence (CAPS) markers taken from the public domain or designed from public sequences (Table 1). PCR, linkage analysis, and QTL mapping followed the procedures described by Ji et al. (2007a). The program MAPMAKER/QTL 1.1 (Lincoln et al., 1993) was applied to identify and map the resistance loci and also obtain estimates of the percentage of phenotypic variation explained by each locus as well as components of variance for each resistance locus. Analysis of variance and/or Duncan's multiple range test in SAS (version 9; SAS Institute, Cary, NC) were used to analyze the association of molecular markers with disease resistance in the population segregating for TYLCV resistance, and the TYLCV resistance in the replicated trial of RILs.

\section{Results}

S. CHILENSE INTROGRESSIONS IN TYLCV-RESISTANT BREEDING LINES. TYLCV-resistant breeding lines derived from $S$. chilense accessions LA1932, LA2779, and their intercrosses (LA2779/ LA1932) were screened with over 400 molecular markers from the tomato genome to identify introgressions that may carry other TYLCV resistance loci in addition to the $T y-3$ locus reported previously (Ji et al., 2007a). Prior information indicated possible $S$. chilense introgressions on tomato chromosomes 11 , 


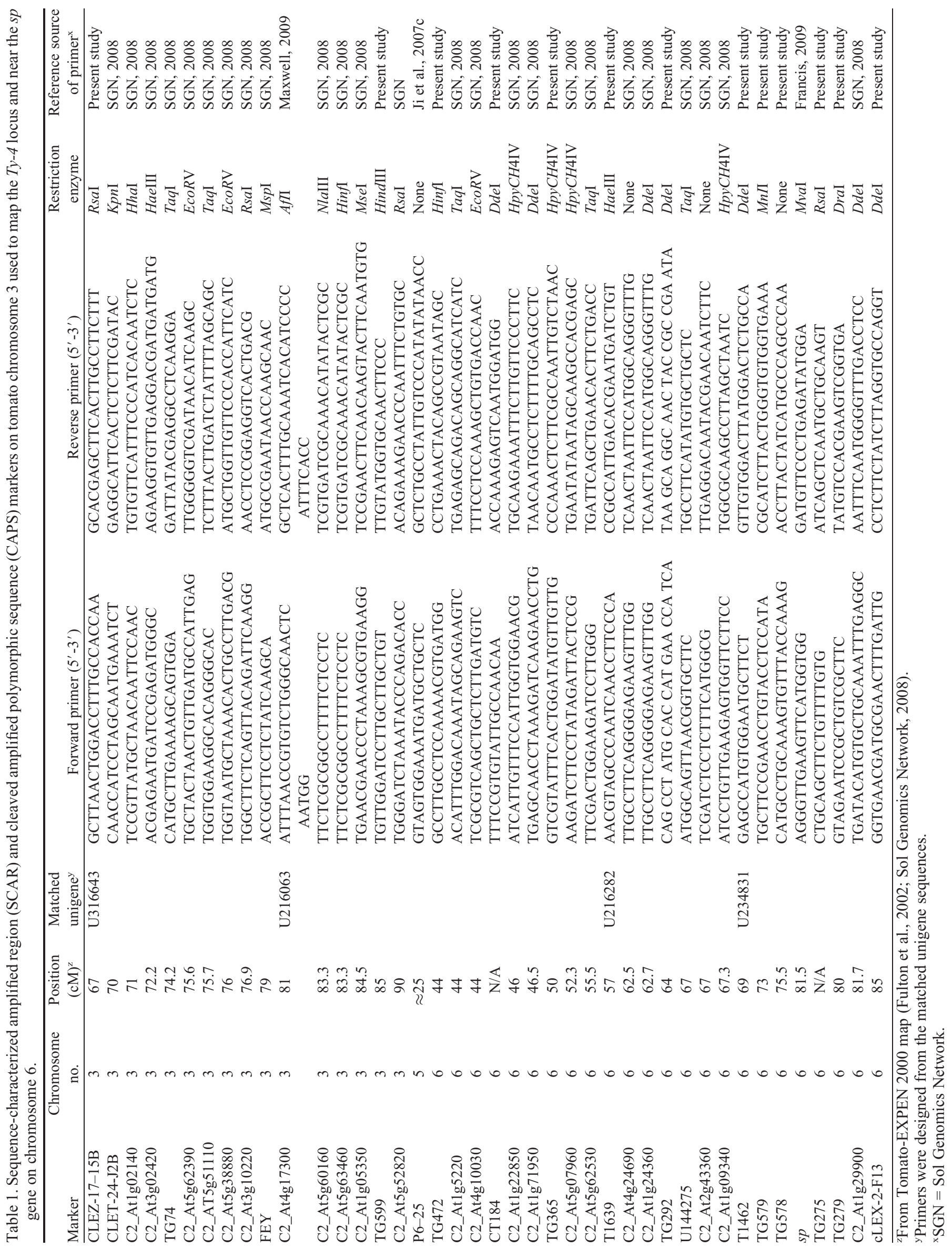


12, 3, and 7 (Y. Ji and J. Scott, unpublished data; Zamir et al. 1994). Therefore, we initially screened the resistant breeding lines with molecular markers on these four chromosomes. The early LA1932-derived line 960719 was shown to carry two additional $S$. chilense introgressions in addition to the introgression in the $T y$-3 region reported previously (Ji et al., 2007a): one is $\approx 35 \mathrm{cM}$, spanning markers from TG472 to the $s p$ gene and TG275 on the long arm of chromosome 6 , and the other is $\approx 14 \mathrm{cM}$, spanning markers from C2_At1g02140 to TG599 on the long arm of chromosome 3 (Fig. 1). Molecular marker analysis also indicated that the early LA1932-derived line 960729 carries only the latter additional introgression besides the Ty-3 introgression. Advanced breeding lines derived from LA2779/LA1932, including line 040980 used for segregation analysis, carry the same introgressions on chromosomes 3 and 6 as did their early ancestor line 090729 . Molecular marker analysis in the present study indicated that both introgressed segments in these lines originated from LA1932. Other regions of the tomato genome were also screened with molecular markers, with an average of one marker every $5 \mathrm{cM}$, but no $S$. chilense introgression was detected in these regions (data not shown).

Mapping of the TYLCV resistance LOCI. Analysis of variance for the population segregating for introgressions on chromosomes 3 and 6 (Ty-3 region) indicated that all the four molecular markers contained within the $S$. chilense introgression on chromosome 6 were significantly associated with disease severity ratings. For example, the SCAR marker P625 designed from bacterial artificial chromosome (BAC) clone 56B23 displayed the highest association with the TYLCV disease severity ratings (Table 2). Similarly, all 12 markers contained within the $S$. chilense introgression on chromosome 3, such as C2_At4g17300, a CAPS marker derived from a cosII marker, were also significantly associated with disease severity ratings, but to a lesser degree compared with markers from chromosome 6 (Table 2). There was no significant interaction between the genotypes of the two markers P6-25 and C2_At4g17300 (Table 2). However, genotypes with $S$. chilene alleles at both marker loci displayed the highest level of resistance, while genotypes with $S$. lycopersicum alleles at both loci showed the severest TYLCV disease (Table 3).

$T y$-3 was mapped to the marker interval between cLEG-31-P16 (20 cM) and C2_At5g41480 (26 cM) on the long arm of chromosome 6 (Fig. 2). A new TYLCV resistance locus, $T y-4$, was mapped in the present study to the marker interval between C2_At4g17300 (81 cM) and C2_At5g60160 (83.3 cM) on the long arm of chromosome 3. $T y$-3 and $T y-4$ loci had more dominance than additivity, with dominance-to-additive ratios of 0.70 and 1.06 , respectively (Table 4). About $60 \%$ of the variance in the TYLCV resistance in the population was explained by the $T y$ 3 locus, while the $T y-4$ locus accounted for only $\approx 16 \%$ of the variance, suggesting Ty-3 had a major effect on resistance, while $T y-4$ had a lesser effect.
Table 2. Analysis of variance for the association between markers C2_At4g17300 (linked to $T y-4$ ) on tomato chromosome 3 or P6-25 (linked to $T y-3$ ) on chromosome 6 and the average disease severity of progenies from a plant heterozygous for both Solanum chilense introgressions on chromosome 3 and 6 , respectively, which were inoculated with tomato yellow leaf curl virus (TYLCV).

\begin{tabular}{|c|c|c|c|c|c|c|}
\hline \multicolumn{3}{|c|}{ Genotype $^{z}$} & \multirow{2}{*}{\multicolumn{2}{|c|}{ Disease severity $(0-4 \text { scale })^{y}$}} & \multirow[b]{3}{*}{ F value } & \multirow[b]{3}{*}{$P>\mathrm{F}^{\mathrm{x}}$} \\
\hline \multirow{2}{*}{$\begin{array}{l}\text { C2_At4g17300 } \\
(T y-4)\end{array}$} & \multirow{2}{*}{$\begin{array}{l}\text { P6-25 } \\
(T y-3)\end{array}$} & \multirow{2}{*}{$\begin{array}{c}\text { Plants } \\
\text { (no.) }\end{array}$} & & & & \\
\hline & & & Mean & Range & & \\
\hline $\mathrm{S}$ & $\mathrm{S} / \mathrm{H} / \mathrm{R}$ & 48 & 1.48 & $0-3.5$ & $19.3^{\mathrm{w}}$ & $<0.0001$ \\
\hline $\mathrm{H}$ & $\mathrm{S} / \mathrm{H} / \mathrm{R}$ & 106 & 0.63 & $0-3.0$ & & \\
\hline $\mathrm{R}$ & $\mathrm{S} / \mathrm{H} / \mathrm{R}$ & 47 & 0.78 & $0-2.5$ & & \\
\hline $\mathrm{S} / \mathrm{H} / \mathrm{R}$ & $\mathrm{S}$ & 50 & 2.1 & $0-3.5$ & $129.4^{\mathrm{v}}$ & $<0.0001$ \\
\hline $\mathrm{S} / \mathrm{H} / \mathrm{R}$ & $\mathrm{H}$ & 110 & 0.53 & $0-2.0$ & & \\
\hline $\mathrm{S} / \mathrm{H} / \mathrm{R}$ & $\mathrm{R}$ & 41 & 0.26 & $0-1.5$ & & \\
\hline $\mathrm{S} / \mathrm{H} / \mathrm{R}$ & $\mathrm{S} / \mathrm{H} / \mathrm{R}$ & 201 & 0.87 & $0-3.5$ & $0.49^{\mathrm{u}}$ & 0.7420 \\
\hline
\end{tabular}

${ }^{\mathrm{z}} \mathrm{R}=$ homozygous for the Solanum chilense allele, $\mathrm{S}=$ homozygous for the Solanum lycopersicum allele, $\mathrm{H}=$ heterozygous, $\mathrm{S} / \mathrm{H} / \mathrm{R}=$ all three different genotypes were observed for the marker in a given group of plants.

$\mathrm{y}_{0}=$ no symptoms, 1 = slight symptoms visible only on close inspection, 2 = intermediate symptoms visible on part of the plant, $3=$ severe symptoms over the entire plant, $4=$ severe symptoms and stunting; intermediate scores $(0.5,1.5$, etc.) were incorporated to allow for more precise disease severity ratings.

${ }^{x}$ Probability that the $\mathrm{F}$ value is not significant; a probability $\leq 0.05$ indicates a significant $\mathrm{F}$ value.

${ }^{w}$ For marker C2_At4g17300.

"For marker P6-25.

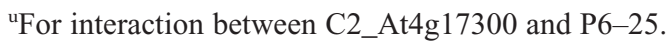


Table 3. Tomato yellow leaf curl virus disease severity for different combinations of genotypes for markers C2_At4g17300 (linked to $T y-4$ ) on tomato chromosome 3 or P6-25 (linked to $T y-3$ ) on chromosome 6 .

\begin{tabular}{|c|c|c|c|c|}
\hline \multicolumn{3}{|c|}{ Genotype $^{z}$} & \multirow{2}{*}{\multicolumn{2}{|c|}{$\begin{array}{c}\text { Disease } \\
\text { severity }(0-4 \text { scale })^{y}\end{array}$}} \\
\hline \multirow{2}{*}{$\begin{array}{l}\text { C2_At4g17300 } \\
(T y-4)\end{array}$} & \multirow{2}{*}{$\begin{array}{l}\text { P6-25 } \\
(T y-3)\end{array}$} & \multirow{2}{*}{$\begin{array}{c}\text { Plants } \\
\text { (no.) }\end{array}$} & & \\
\hline & & & Mean & Range \\
\hline $\mathrm{S}$ & $\mathrm{S}$ & 16 & 2.66 & $2-3.5$ \\
\hline S & $\mathrm{H}$ & 23 & 0.96 & $0-2.0$ \\
\hline S & $\mathrm{R}$ & 9 & 0.72 & $0-1.5$ \\
\hline $\mathrm{H}$ & $\mathrm{S}$ & 21 & 1.83 & $0-3.0$ \\
\hline $\mathrm{H}$ & $\mathrm{H}$ & 64 & 0.41 & $0-2.0$ \\
\hline $\mathrm{H}$ & $\mathrm{R}$ & 21 & 0.07 & $0-0.5$ \\
\hline $\mathrm{R}$ & $\mathrm{S}$ & 13 & 1.85 & $1-2.5$ \\
\hline $\mathrm{R}$ & $\mathrm{H}$ & 23 & 0.43 & $0-1.5$ \\
\hline $\mathrm{R}$ & $\mathrm{R}$ & 11 & 0.23 & $0-1.5$ \\
\hline
\end{tabular}

${ }^{\mathrm{z}} \mathrm{R}=$ homozygous for the Solanum chilense allele, $\mathrm{S}=$ homozygous for the Solanum lycopersicum allele, $\mathrm{H}=$ heterozygous.

${ }^{\mathrm{y}} 0=$ no symptoms, $1=$ slight symptoms visible only on close inspection, 2 = intermediate symptoms visible on part of the plant, 3 = severe symptoms over the entire plant, $4=$ severe symptoms and stunting; intermediate scores $(0.5,1.5$, etc. $)$ were incorporated to allow for more precise disease severity ratings.

REDUCED RECOMBINATION IN THE $\boldsymbol{S}$. CHILENSE INTROGRESSED SEGMENT. The recombination length for the whole $S$. chilense introgressed segment from C2_At1g02140 to TG599 on chromosome 3 in the LA2779/LA1932-derived advanced breeding lines was estimated to be $4.2 \mathrm{cM}$ (Fig. 2), about a 2.5 -fold reduction compared with $14 \mathrm{cM}$ in length from the tomato reference map (Fulton et al., 2002; Sol Genomics Network, 2008). Similarly, recombination was greatly reduced in the introgressed segment on chromosome 6, where only one recombinant was found among 201 progeny, giving an estimation of 0.25 cM for the introgression from cLET-31-P16 to C2_At5g41480, which was nearly a 24-fold reduction compared with the same region of $6 \mathrm{cM}$ in length from the tomato reference map.

Enhancing TYLCV Resistance by PYRAMiding $\boldsymbol{T}_{\boldsymbol{Y}}-3$ AND TY-4. Analysis of variance for RILs containing $T y-3$ alone or in combination with $T y-4$ showed significant differences for TYLCV resistance among these lines (Table 5) with no significant difference among the replicates (data not shown). All RILs containing $T y-3$ had significantly higher levels of TYLCV resistance than the susceptible controls, as well as the $\mathrm{F}_{1}$ hybrids heterozygous for $T y-1$. The two RILs containing $T y$ 3 and $T y-4$ (074766-Y3 and 024525-2) were significantly more resistant than those with $T y-3$ alone. Furthermore, plants with homozygous and/or heterozygous $T y-3$ and $T y-4$ had lower mean disease severity scores than did plants with only $T y-3$ in the mapping population (Tables 2 and 3). The level of TYLCV resistance also varied significantly among the four RILs containing $T y-3$ without $T y-4$ (Table 5), suggesting that additional TYLCV resistance loci besides $T y-3$ and $T y-4$ may exist in these lines.

\section{Discussion}

TY-4, A MinOR TYLCV RESISTANCE LOCUS. The Ty-3 locus was mapped to the marker interval between cLEG-31-P16 (20 cM) and C2_At5g41480 (26 cM) on the long arm of chromosome 6 from the present investigation, which is consis- tent with the previous report (Ji et al., 2007a). About $60 \%$ of the variance in the TYLCV resistance in the segregating population can be explained by $T y-3$ locus, suggesting that $T y-3$ is a major locus responsible for TYLCV resistance, a finding also consistent with the previous report (Ji et al., 2007a). The Ty-3 locus was shown to be effective against monopartite TYLCV and bipartite ToMoV (Ji et al., 2007a). In the present study, we showed that $T y-4$ accounted for about $16 \%$ of the variation and thus would be considered a minor locus compared with $T y-3$. An early report also suggested a minor association between an introgression from LA1969 on chromosome 3 and the TYLCV tolerance (Zamir et al., 1994). Ty-4 was effective against TYLCV, but we did not test bipartite begomoviruses. However, inbreds with $T y-3$ and $T y-4$ have had greater resistance than lines with $T y-3$ alone in Guatemala (D.P. Maxwell, unpublished data), suggesting that $T y-4$ is effective against multiple (up to seven) bipartite begomoviruses that were reported to be present there (Nakhla et al., 2005).

Combining $\boldsymbol{T} \boldsymbol{Y}-3$ and $\boldsymbol{T} \boldsymbol{Y}$-4 LOCI by MAS. Plants carrying $T y$ 3 and $T y-4$ loci from the mapping population and RILs showed excellent levels of TYLCV resistance (Tables 2, 3, and 5). These findings support multigenic control of TYLCV resistance in the $S$. chilense accessions, as observed previously in a study of TYLCV and ToMoV resistance in the backcross progenies derived from various $S$. chilense accessions in which segregation ratios could not be explained by a single dominant gene (Scott et al., 1996). Inheritance and QTL studies also suggested involvement of at least two loci for TYLCV or ToMoV resistance (Agrama and Scott, 2006; Griffiths and Scott, 2001). The resistance of genotypes homozygous for $T y-3$ and $T y-4$ was significantly higher than that of genotypes with $T y-3$ alone, which in turn were significantly higher than commercial hybrids heterozygous for $T y-1$ (Table 5). However, it has been easier to develop commercially acceptable hybrid cultivars using $T y-1$ or $T y-2$ because they are single dominant genes with high levels of resistance as opposed to using resistance from $T y$ 3 and/or Ty-4 from $S$. chilense accessions LA1932 and LA2779, which require more than one gene for the best resistance (Griffiths and Scott, 2001). However, with the discovery of $T y-4$ and the development of markers tightly linked to $T y-3$ and $T y-4$, it is now possible for the first time to use MAS to rapidly incorporate high resistance levels into recurrent parent lines with nearly the same ease as incorporating $T y-1$ or $T y-2$. One approach would be to put $T y-3$ and $T y-4$ into both parents of a hybrid. The data in Tables 2 and 3 indicate it might also be possible to have one parent homozygous for both loci while the other could have only $T y-3$ or perhaps only $T y-4$. Differences in disease severity among the four RILs containing $T y-3$ alone suggested additional resistance gene(s) may exist in some LA1932derived breeding lines. This claim was supported by analysis of TYLCV resistance among the $\mathrm{F}_{2}$ progeny of a LA1932-derived line containing neither $T y-3$ nor $T y-4$, which segregated for the TYLCV resistance (Y. Ji and J. Scott, unpublished data).

REDUCED RECOMBINATION IN THE $\boldsymbol{S}$. CHILENSE INTROGRESSIONS CARRYING THE TYLCV Resistance LOCI. A nearly 2.5-fold reduction of recombination relative to the tomato reference map (Fulton et al., 2002) was observed in the introgressed segments carrying the $T y-4$ locus, which is most likely due to sequence divergence between $S$. chilense and the cultivated tomato. Reduction of recombination between homeologous chromosomes due to nucleotide divergence was also observed in introgressions from many other tomato wild species (Canady 
et al., 2006). A genome-wide reduction in recombination frequencies was observed for the introgressed S. lycopersicoides segments in the background of cultivated tomato, often to as low as $0 \%$ to $10 \%$ of the normal levels (Canady et al., 2006), while recombination within introgressed segments derived from $S$. pennellii or $S$. habrochaietesis typically are about $15 \%$ to $30 \%$ of the normal levels (Alpert and Tanksley, 1996; Monforte and Tanksley, 2000). In the present study, we observed a much greater reduction of recombination $(\approx 24$-fold $)$ in the introgressed segments carrying the $T y$-3 locus than the 2.5 -fold reduction in the introgression carrying the $T y-4$ locus. This greater reduction of recombination may be due to the relatively smaller introgressed segment on chromosome 6 , which is $\approx 6 \mathrm{cM}$ in length compared with the 14-cM Ty-4 introgression. This assertion is in agreement with the previous study of a library of $S$. lycopersicoides introgression lines in which shorter introgressions usually demonstrated greater reductions in homeologous recombination than larger introgressions (Canady et al., 2006).

Reduced recombination within the alien introgressed segments carrying genes of interest may pose potential disadvantages for plant breeders. Plant breeders usually have to make extra efforts (such as more time and larger selecting populations) to break down linkage drag and remove the excessive alien chromatin that causes detrimental effects on the horticultural features of cultivars. Additionally, reduced recombination within introgressed segments may make it difficult to combine tightly linked resistance genes from different sources (in trans configuration) into a single inbred parent (in cis orientation). This is the case for the root-knot nematode resistance $M i$ gene and the TYLCV resistance gene $T y-1$ (Ji et al., 2007b). Numerous tomato breeding programs around the world tried for many years to bring these two genes together in coupling phase, but this was achieved only recently by Seminis Inc. with the assistance of molecular markers (Hoogstraten and Braun, 2005).

Pyramiding resistance genes OF VARIOUS ORIGINS TO EXPAND THE LEVEL AND RANGE OF TYLCV RESISTANCE. The linkage drag situation, however, could be significantly improved using molecular markers tightly linked to genes of interest in the introgressed segments because these markers could facilitate the identification of recombinants with shorter introgressions but still carrying the target gene(s) in succeeding generations. Similarly, with the assistance of molecular markers, it is

Table 4. Components of variance for the resistance loci in the mapping population segregating for tomato $T y-3$ and $T y-4$ loci.

\begin{tabular}{llcccccr}
\hline Locus & Marker interval & $\begin{array}{c}\text { Mean disease } \\
\text { severity }\end{array}$ & $\begin{array}{c}\text { Additive } \\
\text { variance }\end{array}$ & $\begin{array}{c}\text { Dominance } \\
\text { variance }\end{array}$ & $\begin{array}{c}\text { Dominance-to- } \\
\text { additive ratio }\end{array}$ & $\begin{array}{c}\text { Variance } \\
\text { Log-likelihood }\end{array}$ & explained (\%) \\
\hline Ty-3 & CLEG-31-P16 - C2_At5g41480 & 2.05 & -0.9310 & -0.6481 & 0.70 & 39.6 & 59.6 \\
$T y-4$ & C2_At4g17300 - C2_At5g60160 & 1.46 & -0.4258 & -0.4526 & 1.06 & 7.4 \\
\hline
\end{tabular}


Table 5. Tomato yellow leaf curl virus (TYLCV) disease severity for tomato recombinant inbred lines containing $T y-3$ with or without $T y-4$.

\begin{tabular}{lllcc}
\hline Line & \multicolumn{1}{c}{ Genotype $^{\mathrm{z}}$} & Resistance source & Plants (no.) & $\begin{array}{c}\text { Mean disease } \\
\text { severity (0-4 scale) }\end{array}$ \\
\hline 'Horizon' & Susceptible & Susceptible & 36 & $2.85 \mathrm{a}$ \\
'Tygress' & Ty1ty1 & LA1969 & 35 & $1.87 \mathrm{~b}$ \\
'SecuriTy 28' & Ty1ty1 & LA1969 & 32 & $1.48 \mathrm{c}$ \\
$074766-7$ & Ty3Ty3ty4ty4 & LA2779/LA1932x & 35 & $1.1 \mathrm{~d}$ \\
$074766-Y 5$ & Ty3Ty3ty4ty4 & LA2779/LA1932 & 36 & $0.93 \mathrm{de}$ \\
051005 & Ty3Ty3ty4ty4 & LA2779/LA1932 & 36 & $0.78 \mathrm{ef}$ \\
8602 & Ty3Ty3ty4ty4 & LA2779 & 35 & $0.60 \mathrm{fg}$ \\
$051018-Y 6$ & Ty3Ty3ty4ty4 & LA2779/LA1932 & 35 & $0.47 \mathrm{~g}$ \\
024525-2 & Ty3Ty3Ty4Ty4 & LA2779/LA1932 & 36 & $0.18 \mathrm{~h}$ \\
074766-Y3 & Ty3Ty3Ty4Ty4 & LA2779/LA1932 & 35 & $0.10 \mathrm{~h}$
\end{tabular}

${ }^{\mathrm{z}}$ For brevity, the '-' is omitted in the name of an allele, for example $T y 1=T y-1$.

${ }^{y_{0}}=$ no symptoms, $1=$ slight symptoms visible only on close inspection, $2=$ intermediate symptoms visible on part of the plant, $3=$ severe symptoms over the entire plant, $4=$ severe symptoms and stunting; intermediate scores $(0.5,1.5$, etc. $)$ were incorporated to allow for more precise disease severity ratings. Means disease severity with the same letter are not significantly different at $P \leq 0.05$ via Duncan's multiple range test.

${ }^{\mathrm{x}} T y-3$ and $T y-4$ originated from LA1932 in the lines derived from LA2779/LA1932 (see text for detail).

possible to systematically incorporate multiple resistance genes of different origins into a single elite genotype to enhance the degree of resistance or tolerance to major pathogens such as begomoviruses. Furthermore, pyramiding resistance genes originating from different sources could also expand the resistance against a wider range of begomoviruses (Vidavski, 2007).

Currently, four TYLCV resistance loci (Ty-1 through $T y-4)$ have been mapped to different regions of the tomato genome, each of which can be tagged with tightly linked PCR-based molecular markers that have been developed in previous and current studies. These resistance loci originate from different wild tomato accessions and possess various modes of TYLCV resistance. $T y-1$, which originated from $S$. chilense accession LA1969 and is nearly completely dominant to TYLCV, is not effective against ToMoV, a bipartite begomovirus (Ji et al., 2007b; Zamir et al., 1994). Ty-2, which originated from $S$. habrochaites (Kalloo and Banerjee, 1990) and showed completely dominant TYLCV inheritance, is also not effective against ToMoV (Hanson et al., 2000; Ji et al., 2007b). Neither gene is effective against all strains of TYLCV. Unlike $T y-1$ and $T y-2$, the more recently mapped begomovirus resistant locus $T y-3$, which is found in several $S$. chilense accessions such as LA2779 and LA1932, is more additive in nature and is effective against TYLCV and ToMoV (Agrama and Scott, 2006; Ji et al., 2007a). Ty-4 originated from S. chilense accession LA1932 and has a smaller effect than $T y-3$. Robust PCR-based markers developed from current and previous studies such as JB-1, T0302, P6-25, and C2_At4g17300 can be used to effectively tag $T y-1$ though $T y-4$ loci, respectively, and thus enhance selection efficiency (de Castro et al., 2007; Garcia et al., 2007; Ji et al., 2007c; Ji et al., 2009). In addition, these PCRbased markers can expedite the process of pyramiding these resistance loci into a single elite genotype, thus elevating the level of resistance as well as broadening the range of begomovirus resistance. Lines with different resistance gene combinations need to be tested against a range of begomoviruses to determine their effects, as they can be unpredictable (Vidavski,
2007). Also, the effects of linkage drag may well increase as genes are pyramided and this will have to be addressed.

\section{Literature Cited}

Agrama, H.A. and J.W. Scott. 2006. Quantitative trait loci for tomato yellow leaf curl virus and tomato mottle virus resistance in tomato. J. Amer. Soc. Hort. Sci. 131:267-272.

Alpert, K.B. and S.D. Tanksley. 1996. Highresolution mapping and isolation of a yeast artificial chromosome contig containing fw2.2: A major fruit weight quantitative trait locus in tomato. Proc. Natl. Acad. Sci. USA 93:15503-15507.

Canady, M.A., Y. Ji, and R.T. Chetelat. 2006. Homeologous recombination in Solanum lycopersicoides introgression lines of cultivated tomato. Genetics 174:1775-1788.

de Castro, A.P., J.M. Blanca, M.J. Díez, and F.N. Viñals. 2007. Identification of a CAPS marker tightly linked to the tomato yellow leaf curl disease resistance gene $T y-1$ in tomato. Eur. J. Plant Pathol. 117:347-356.

Foolad, M.R. and A. Sharma. 2005. Molecular markers as selection tools in tomato breeding. Acta Hort. 695:225-240. Francis, D.M. 2009. PCR-based markers that are polymorphic between Solanum esculentum and S. pimpinellifolium accession LA1589. 8 Mar. 2009. <http://164.107.85.47:8003/cgi-bin/molecular_markers.pl>.

Fulton, T.M., R. Van der Hoeven, N.T. Eannetta, and S.D. Tanksley. 2002. Identification, analysis, and utilization of conserved ortholog set markers for comparative genomics in higher plants. Plant Cell 14:1457-1467.

Garcia, B.E., E. Graham, K.S. Jensen, P. Hanson, L. Mejía, and D.P. Maxwell. 2007. Co-dominant SCAR marker for detection of the begomovirus-resistance $T y$ - 2 locus derived from Solanum habrochaites in tomato germplasm. Rpt. Tomato Genet. Coop. 57:21-24. Griffiths, P.D. 1998. Inheritance and linkage of geminivirus resistance genes derived from Lycopersicon chilense (Dunal) in tomato (Lycopersicon esculentum Mill). Ph.D. Diss. University of Florida, Gainesville.

Griffiths, P.D. and J.W. Scott. 2001. Inheritance and linkage of tomato mottle virus resistance genes derived from Lycopersicon chilense accession LA 1932. J. Amer. Soc. Hort. Sci. 126:462-467.

Hanson, P.M., D. Bernacchi, S. Green, S.D. Tanksley, V. Muniyappa, A.S. Padmaja, H. Chen, G. Kuo, D. Fang, and J. Chen. 2000. Mapping a wild tomato introgression associated with tomato yellow leaf curl virus resistance in a cultivated tomato line. J. Amer. Soc. Hort. Sci. 15:15-20.

Hanson, P.M., S.K. Green, and G. Kuo. 2006. Ty-2, a gene on chromosome 11 conditioning geminivirus resistance in tomato. Rpt. Tomato Genet. Coop. 56:17-18.

Hoogstraten, J.G. and C.J. Braun. 2005. Methods for coupling resistance alleles in tomato. 10 Mar. 2009. <http://www.wipo.int/ pctdb/en/wo.jsp?wo=2005079342>.

Ji, Y., D.J. Schuster, and J.W. Scott. 2007a. Ty-3, a begomovirus resistance locus near the tomato yellow leaf curl virus resistance locus $T y-1$ on chromosome 6 of tomato. Mol. Breed. 20:271-284.

Ji, Y., J.W. Scott, and D.J. Schuster. 2009. Toward fine mapping of the tomato yellow leaf curl virus resistance gene $T y-2$ on chromosome 11 of tomato. HortScience (in press).

Ji, Y., J.W. Scott, P. Hanson, E. Graham, and D.P. Maxwell. 2007b. Sources of resistance, inheritance, and location of genetic loci conferring resistance to members of the tomato-infecting begomoviruses, p. 343-362. In: H. Czosnek (ed.). Tomato yellow leaf curl virus disease: Management, molecular biology, breeding for resistance. Kluwer, Dordrecht, The Netherlands. 
Ji, Y., M.S. Salus, B. van Betteray, J. Smeets, K.S. Jensen, C.T. Martin, L. Mejía, J.W. Scott, M.J. Havey, and D.P. Maxwell. 2007c. Codominant SCAR markers for detection of the $T y-3$ and $T y-3 a$ loci from Solanum chilense at $25 \mathrm{cM}$ of chromosome 6 of tomato. Rpt. Tomato Genet. Coop. 57:25-28.

Kalloo, G. and M.K. Banerjee. 1990. Transfer of tomato leaf curl virus resistance from Lycopersicon hirsutum f. glabratum to L. esculentum. Plant Breed. 105:156-159.

Lincoln, S., M. Daly, and E.S. Lander. 1993. Mapping genes controlling quantitative traits with MAPMAKER/QTL 1.1: A tutorial and reference manual. Whitehead Inst. Tech. Rpt., 2nd ed. Whitehead Institute, Cambridge, MA.

Maxwell, D.P. 2009. Introgression at $81 \mathrm{cM}$ on chromosome 3 associated with Gc171. 8 Mar. 2009. <http://www. plantpath.wisc.edu/GeminivirusResistantTomatoes/Markers/P381.pdf>.

Monforte, A.J. and S.D. Tanksley. 2000. Fine mapping of a quantitative trait locus (QTL) from Lycopersicon hirsutum chromosome 1 affecting fruit characteristics and agronomic traits: Breaking linkage among QTLs affecting different traits and dissection of heterosis for yield. Theor. Appl. Genet. 100:471-479.

Nakhla, M.K., A. Sorenson, L. Mejía, P. Ramírez, J.P. Karkashian, and D.P. Maxwell. 2005. Molecular characterization of tomato-infecting begomoviruses in Central America and development of DNA-based detection methods. Acta Hort. 695:277-288.

Olson, S.M., D.N. Maynard, G.J. Hochmuth, C.S. Vavrina, W.M. Stall, T.A. Kucharek, S.E. Webb, T.G. Taylor, S.A. Smith, and E. Simonne. 2008. Tomato production in Florida, p. 409-429. In: S.M. Olson and E. Simonne (eds.). Vegetable production handbook for Florida 2007-2008. Vance Publishing, Lincolnshire, IL.

Omer, A.D., M.W. Johnson, B.E. Tabashnik, H.S. Costa, and D.E. Ullman. 1993. Sweet-potato whitefly resistance to insecticides in Hawaii: Intra-island variation is related to insecticide use. Entomol. Exp. Appl. 67:173-182.
Pico, B., M.J. Diez, and F. Nuez. 1996. Viral diseases causing the greatest economic losses to the tomato crop. II. The tomato yellow leaf curl virus: A review. Scientia Hort. 67:151-196.

Polston, J.E. and P.K. Anderson. 1997. The emergence of whiteflytransmitted geminiviruses in tomato in the western hemisphere. Plant Dis. 81:1358-1369.

Scott, J.W. 2007. Breeding for resistance to viral pathogens, p. 447474. In: M.K. Razdan and A.K. Mattoo (eds.). Genetic improvement of solanaceous crops. Vol. 2: Tomato. Science Publisher, Enfield, $\mathrm{NH}$.

Scott, J.W., J.A. Bartz, H.H. Bryan, P.H. Everett, D.D. Gull, T.K. Howe, P.J. Stoffella, and R.B. Volin. 1985. 'Horizon': A fresh market tomato with concentrated fruit set. Florida Agr. Expt. Sta. Circ. S-323:8.

Scott, J.W., M.R. Stevens, J.H.M. Barten, C.R. Thome, J.E. Polston, D.J. Schuster, and C.A. Serra. 1996. Introgression of resistance to whitefly-transmitted geminiviruses from Lycopersicon chilense to tomato, p. 357-367. In: D. Gerling and R.T. Mayer (eds.). Bemisia 1995: Taxonomy, biology, damage control, and management. Intercept, Andover, UK.

Sol Genomics Network. 2008. Tomato-EXPEN 2000: S. lycopersicum LA925 $\times$ S. pennellii LA716 type F2.2000. 18 Dec. 2008. <http:// www.sgn.cornell.edu/cview/map.pl?map_id=9\&show_offsets=1\& show_ruler $=1>$.

Vidavski, F.S. 2007. Exploitation of resistance genes found in wild tomato species to produce resistant cultivars; pile up of resistant genes, p. 363-372. In: H. Czosnek (ed.). Tomato yellow leaf curl virus disease: Management, molecular biology, breeding for resistance Kluwer, Dordrecht, The Netherlands.

Zamir, D., I. Eksteinmichelson, Y. Zakay, N. Navot, M. Zeidan, M. Sarfatti, Y. Eshed, E. Harel, T. Pleban, H. Vanoss, N. Kedar, H.D. Rabinowitch, and H. Czosnek. 1994. Mapping and introgression of a tomato yellow leaf curl virus tolerance gene, Ty-1. Theor. Appl. Genet. 88:141-146. 